\title{
sciendo
}

\section{Standard Project Risk Analysis Approach}

\section{Tena Žužek}

Faculty of Mechanical Engineering, University of Ljubljana, Ljubljana, Slovenia Lidija Rihar

Faculty of Mechanical Engineering, University of Ljubljana, Ljubljana, Slovenia Tomaž Berlec

Faculty of Mechanical Engineering, University of Ljubljana, Ljubljana, Slovenia Janez Kušar

Faculty of Mechanical Engineering, University of Ljubljana, Ljubljana, Slovenia

\section{Abstract}

Background: To stay competitive in a highly unpredictable market of today, companies must be able to manage project risks effectively. The basis for an effective risk management is a thorough risk analysis. Despite the availability of many different risk analysis approaches, companies can be reluctant to use them, since the models are usually complex and very time consuming. Objectives: The main objective is to present a simple, yet effective risk analysis approach that can also serve as a useful basis for resolving project risks. Methods/Approach: The proposed standard risk analysis approach is based on a standard risk model that deals with risk events and impacts separately and therefore allows for a separate planning of preventive and corrective measures. To classify risks and to represent them graphically, a risk map is used. Results: The use of the proposed approach is illustrated on a die-cast tool development project. The approach proved to be very simple to use and it served as a useful basis for resolving the identified risks. Conclusions: The main advantage of the proposed approach is its simplicity and clarity. It can also be used as a quick decision-making tool in a subsequent risk resolving process.

Keywords: risk management, risk analysis, standard risk model, risk map

JEL classification: $\mathrm{O} 22, \mathrm{O} 32$

Paper type: Research article

Received: Nov 22, 2019

Accepted: Apr 19, 2020

Citation: Žužek, T., Rihar, L., Berlec, T., Kušar, J. (2020), "Standard Project Risk Analysis Approach", Business Systems Research, Vol. 11, No. 2, pp. 149-158.

DOI: 10.2478/bsrj-2020-0021

Acknowledgments: This work was supported by the Ministry of Higher Education, Science and Technology of the Republic of Slovenia, Grant No. 1000-15-0510, and by the Slovenian Research Agency, Grant No. P2-0270.

\section{Introduction}

Today, companies are facing more and more complex products, rapid technology changes, ever changing customer demands and unpredictable markets. To survive and remain competitive, companies have to be able to adapt to the competitive 
environment and to manage uncertainties. Risks are one of the key success factors of a project (Krane et al., 2010), therefore it is crucial that they are effectively managed.

Merritt and Smith (2004) defined a risk in the context of a project as a possibility of occurrence of an undesired event or a possibility of the absence of a desired event, and the risk management as a set of techniques for controlling the project uncertainties.

PMBOK® lists risk management as one of the basic areas of successful project management skills (PMI, 2017). Project managers need to be trained to use the appropriate risk management tools throughout the project and not only when adverse effects occur.

A widely accepted risk management process consists of the following five steps: risk identification, risk analysis, risk prioritization, resolving risks, and monitoring risks (Smith and Merritt, 2002; Tonchia, 2018). In this paper, we are going to focus on the risk analysis step.

The risk analysis step is very important, because the companies have neither time nor resources for resolving all of the identified risks. Therefore, risks must be properly evaluated, and resources used only on resolving the most critical ones (Baccarini \& Archer, 2001).

There are many different risk analysis methods available (Chauhan et al., 2018; de Araújo Lima et al., 2019). Some of them evaluate risks qualitatively and others quantitatively (de Araújo Lima et al., 2019). In general, quantitative methods provide results that are more objective yet they rely on detailed numerical data that is rarely available. Therefore, experts' assessments are often applied as an alternative to the objective data (Ferdous et al., 2011). Chauhan et al. (2018) state that experts can be a reliable source of information as they are working on the projects on a daily basis.

In practice, a risk matrix is one of the most widely used risk evaluation tools (Levine, 2012; Li et al., 2018). Risks are categorized into different risk cells, to which specific risk levels are assigned (usually low, moderate, high), based on the evaluation of two components: the probability of risk occurrence and the magnitude of impact (Li et al., 2018). The evaluation can be either qualitative, semi-quantitative, or quantitative (Ni et al., 2010). When quantitative evaluation is applied, a risk matrix can be extended into a continuous graph, called a risk map (Smith \& Merritt, 2002).

One of the drawbacks of a risk matrix approach is that the same quantitative risks can fall into different qualitative risk cells (Levine, 2012). This problem can be solved with a different partition of the matrix: the risk areas, to which the same risk level is assigned should not be rectangular cells but irregularly shaped areas, separated by hyperbolas ( $\mathrm{Ni}$ et al., 2010; Levine, 2012). These hyperbolas, also called the isorisks (Levine, 2012), connect risks with the same quantitative score.

Another possible upgrade of a risk evaluation process is to treat a risk as a combination of two separate entities: a risk event and an impact. With a clear separation between a risk event (cause) and an impact (effect), preventive and corrective measures can be prepared more effectively. Smith and Merritt (2002) call this risk evaluation model a standard risk model.

In this paper, we are going to present a risk analysis approach that combines a standard risk model and a risk map. This combination allows for a simple risk evaluation that supports the cause and effect concept, and provides for a consistent risk categorization. The main aim is to present the proposed approach, and to illustrate its use on a real case example. We want to show that the approach is simple to understand, offers a quick and illustrative risk evaluation, and serves as a good platform for resolving risks. 
The rest of the paper is organized as follows: in the next section, the standard risk model and risk map are described. Next, the standard risk analysis approach is shown on a die-cast tool development project. Finally, in the discussion and the conclusion, the advantages and disadvantages of the approach are discussed and some directions for a future research provided.

\section{Methodology}

\section{Standard Risk Model}

A risk model is a tool for systematic risk management. It facilitates communication between stakeholders and allows for an easier risk identification and analysis (Smith \& Merritt, 2002).

In most cases, risks are treated as a combination of risk probability and risk impact (Markowski \& Sam Mannan, 2008; Ni et al., 2010). This model is referred to as a simple risk model (Smith \& Merritt, 2002). While it is simple to use, this model can also lead to some confusion when resolving risks, since it is very hard to distinguish between the cause and the effect. Smith and Merritt (2002) therefore recommend the use of a standard risk model, where the risk event (cause) and the impact (effect) are dealt with separately.

The standard risk model is shown in Figure 1. It relates three entities: the risk event, the impact, and the total loss. The risk event represents the state that triggers a potential loss, the impact represents a potential consequence of the risk event, and the total loss $\left(L_{t}\right)$ represents the severity of the loss in case of the risk event occurrence. For the risk event and the impact, the drivers must be identified and the probabilities of occurrence determined $\left(P_{e}\right.$ and $\left.P_{i}\right)$.

Figure 1

Standard Risk Model

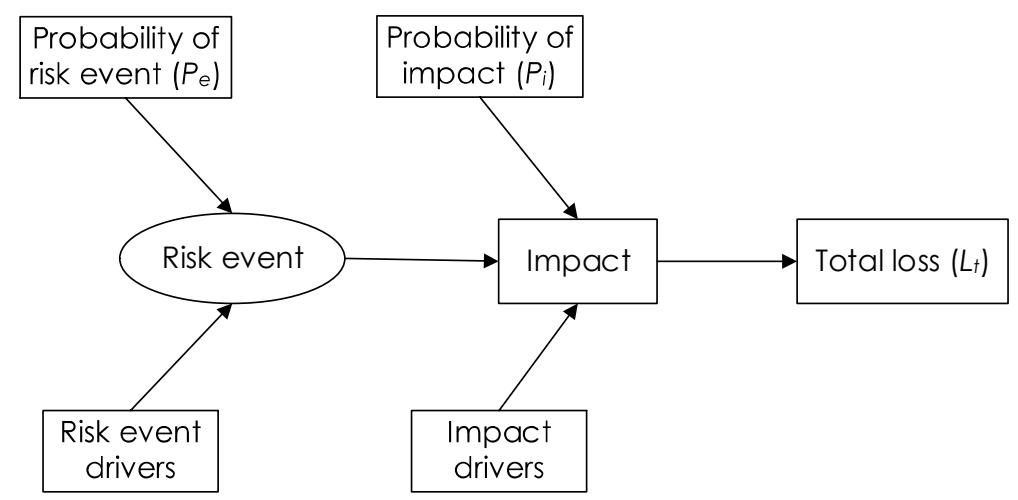

Source: Smith and Merritt (2002)

The probabilities $P_{e}$ and $P_{i}$, and the total loss $L_{t}$ represent subjective assessments, since the objective values are in most cases not available (Ferdous et al., 2011). The assessments are usually based on the experience from previous similar projects, or on decision-making tables prepared by an expert group. Even though the assessments are subjective in nature, they can still support the decision-making (Aven, 2016). The assessed values $P_{e}, P_{i}$ and $L_{t}$ represent the basis for evaluating the expected loss of the risk $L_{e}$, which indicates its severity (Smith \& Merritt, 2002):

$$
L_{e}=P_{e} \cdot P_{i} \cdot L_{t}
$$




\section{Risk Map}

The number of identified risks is usually high, while the available resources for dealing with risks are limited. Therefore, the risks need to be properly classified and resources need to be focused on those risks that pose the greatest danger to the project (Baccarini \& Archer, 2001).

One of the simplest risk prioritization tools is a risk matrix (Levine, 2012). The $x$ axis of a risk matrix represents the magnitude of impact, and the $y$ axis represents the risk probability. The risk matrix is sectioned into cells that are assigned different risk ratings (usually low, moderate, high), based on the evaluation of the two components (Li et al., 2018).

The magnitude of impact and the risk probability can be evaluated qualitatively, semi-quantitatively, or quantitatively ( $\mathrm{Ni}$ et al., 2010). When a standard risk model is used, the evaluation is quantitative, and a risk matrix can be transformed into a continuous graph, called a risk map (Smith \& Merritt, 2002). According to the standard risk model, the $x$ axis of a risk map represents the total loss $L_{t}$ (it can be expressed in units of time, money or quality), and the y axis represents the risk likelihood, which equals the product of the risk event probability $P_{e}$ and the risk impact probability $P_{i}$.

In contrast to the risk matrix, the risk map is not sectioned into predefined risk cells, but into irregularly shaped areas separated by hyperbolas ( $\mathrm{Ni}$ et al., 2010). Thus, a consistent colouring is ensured (Levine, 2012).

The hyperbolas represent the lines with a constant expected loss. This means that all the risks that lie on the same hyperbola lead to the same expected loss. The hyperbolas are also called the isorisks and are defined with the following equation (Levine, 2012):

$$
\frac{L_{e}}{L_{t}}=P_{e} \cdot P_{i}
$$

Using a risk map, project risks can be classified into any number of categories. The simplest classification is a classification into two categories only: critical risks and noncritical risks (Figure 2). In a risk map, critical and non-critical risks are separated by a hyperbola called a threshold line (Smith and Merritt, 2002). The threshold line is defined with equation 2, where Le equals the still acceptable loss for the company.

Figure 2

Risk Map

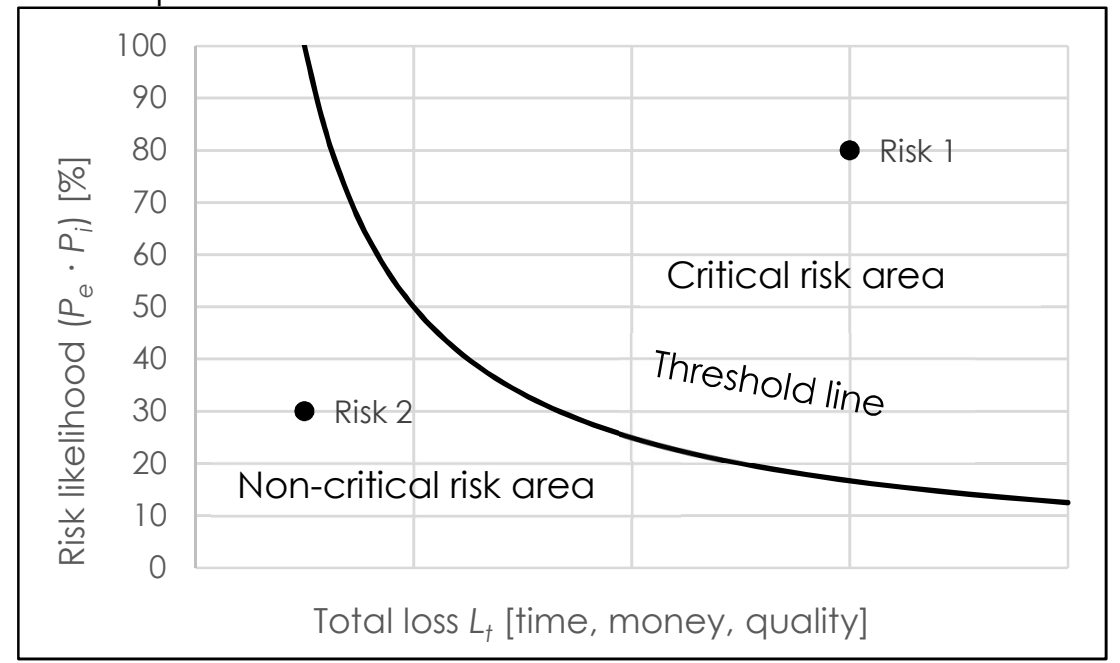

Source: Smith and Merritt (2002) 
The area above the threshold line represents the critical risk area (Risk 1 in Figure 2), and the area below the threshold line represents the non-critical risk area (Risk 2 in Figure 2). For critical risks, adequate measures, both preventive and corrective, need to be prepared to reduce the risk level. The risk level can be reduced by either lowering the risk event probability, the impact probability or by lowering the total loss. The goal is for all the risks to be below the threshold line in the non-critical risk area.

\section{Results: A Die-Cast Development Project}

In the following, the use of the standard project risk analysis approach is shown on a development project of a die-cast tool for an automotive engine component production. The tool was developed and manufactured in a Slovenian SME toolmaking company. The project started with an order from the customer and completed with the confirmation of product samples.

First, the major risk factors (project team, buyer, suppliers, development and technology, manufacture, quality control) were identified using the Ishikawa diagram, and all the possible project risks within the individual factors were found. Then the Work Breakdown Structure (WBS) of the project was thoroughly studied and the identified risks were assigned to individual activities.

According to the standard risk model, the identified risk events were linked to their impacts. Based on the experience with similar projects, the project team assessed the risk event probability $P_{e}$, the impact probability $P_{i}$, and the total loss $L_{t}$. Using the assessed values, the expected loss $L_{e}$ for each risk was calculated using equation 1. The risks were then prioritized by the value of the expected loss. Both, the monetary losses (additional costs) and time losses (delays) were analysed. For illustrative purposes, only the analysis of four monetary-loss related project risks is presented in the following. These risks are summarized in Table 1.

Table 1

Monetary-loss related risks of the die-cast tool development project

\begin{tabular}{|c|c|c|c|c|c|c|c|c|}
\hline Risk & Activity & $\begin{array}{l}\text { Risk Event } \\
\text { Description }\end{array}$ & $P e$ & $\begin{array}{l}\text { Impact } \\
\text { Description }\end{array}$ & $P_{i}$ & $P_{e} \cdot P_{i}$ & $L_{t}[€]$ & Le [€] \\
\hline R1 & $\begin{array}{l}\text { Design } \\
\text { Freeze }\end{array}$ & $\begin{array}{l}\text { Late } \\
\text { confirmation of } \\
\text { documentation } \\
\text { by the buyer }\end{array}$ & 0.8 & $\begin{array}{l}\text { Plan for the } \\
\text { tool not } \\
\text { prepared in } \\
\text { time }\end{array}$ & 0.9 & 0.72 & 5,000 & 3,600 \\
\hline R2 & $\begin{array}{l}\text { Confirma- } \\
\text { tion of first } \\
\text { pieces }\end{array}$ & $\begin{array}{l}\text { Rejection by the } \\
\text { buyer }\end{array}$ & 0.3 & $\begin{array}{l}\text { Corrections of } \\
\text { the method }\end{array}$ & 1.0 & 0.30 & 5,000 & 1,500 \\
\hline R3 & $\begin{array}{l}\text { Manu- } \\
\text { facture of } \\
\text { first pieces }\end{array}$ & $\begin{array}{l}\text { Poor quality of } \\
\text { pieces }\end{array}$ & 0.5 & $\begin{array}{l}\text { Corrections of } \\
\text { the method, } \\
\text { new } \\
\text { manufacture } \\
\text { of pieces }\end{array}$ & 0.8 & 0.40 & 3,000 & 1,200 \\
\hline R4 & $\begin{array}{l}\text { Delivery of } \\
\text { special tool }\end{array}$ & Late delivery & 0.6 & $\begin{array}{l}\text { Manufacture } \\
\text { of special } \\
\text { parts not in } \\
\text { time }\end{array}$ & 0.7 & 0.42 & 500 & 210 \\
\hline
\end{tabular}

Note: For illustrative purposes, only four monetary-loss related risks are listed. The values $P_{e}, P_{i}$ and $L_{+}$were assessed by the project team.

Source: Author's work 
The still acceptable expected loss Le was set at $€ 1,000$. The risk map of the risks listed in Table 1 is shown in Figure 3. One can quickly see that risks R1, R2 and R3 are critical (they lie above the threshold line), while risk R4 is not critical (it lies below the threshold line).

Figure 3

Monetary-Loss Related Risk Map for the Die-Cast Tool Development Project

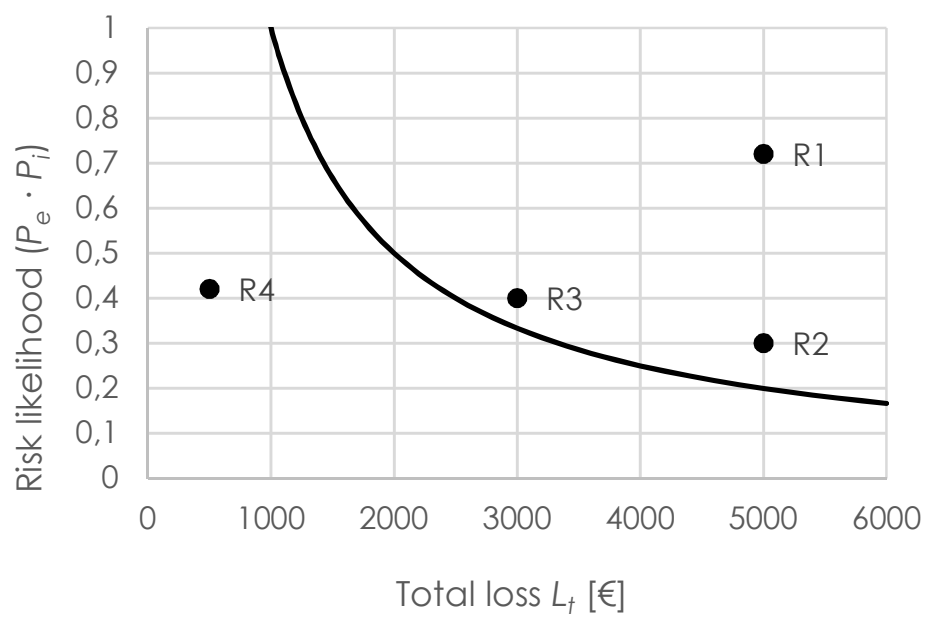

Source: Author's illustration

For the most critical risks, a detailed analysis has been made, risk event drivers and affect drivers identified, and different measures to lower the risk levels prepared. A detailed analysis will be illustrated on the example of risk R1. Risk R 1 is the most critical among the listed risks and it appears as first in the project's timeline. The standard risk model for risk R1 is presented in Figure 4.

It is a known fact that the buyer often confirms the documentation later than originally agreed. Based on the previous experience with the buyer, the project team assessed there is an $80 \%$ chance that the confirmation will be received with a 2 -week delay.

Without the documentation being confirmed, the plan for the tool cannot be completed and the work cannot continue according to the foreseen schedule, which leads to high extra costs. If the buyer is two weeks late with the confirmation, the total loss of the company is assessed to amount to $€ 5,000$. The expected loss equals $€ 3,600$, which is higher than the predetermined still acceptable value of $€ 1,000$. Therefore, adequate measures had to be prepared to lower the expected loss.

First, the risk event drivers were analysed. It turned out that the main reason for the late confirmation of the documentation lies in the fact that the timelines of the buyer are not harmonised with those of the company. It was decided to coordinate the dates before signing the contract and to have the dates fixed in the contract (measure 1). The project team assessed that the probability for the documentation not being confirmed in time reduces to $70 \%$, and at the same time half of the costs are passed on to the buyer in case of a delay. The total loss in that case equals $€ 2,500$, and the expected loss equals $€ 1,575$. 
Figure 4

Standard risk model for risk $\mathrm{R} 1$

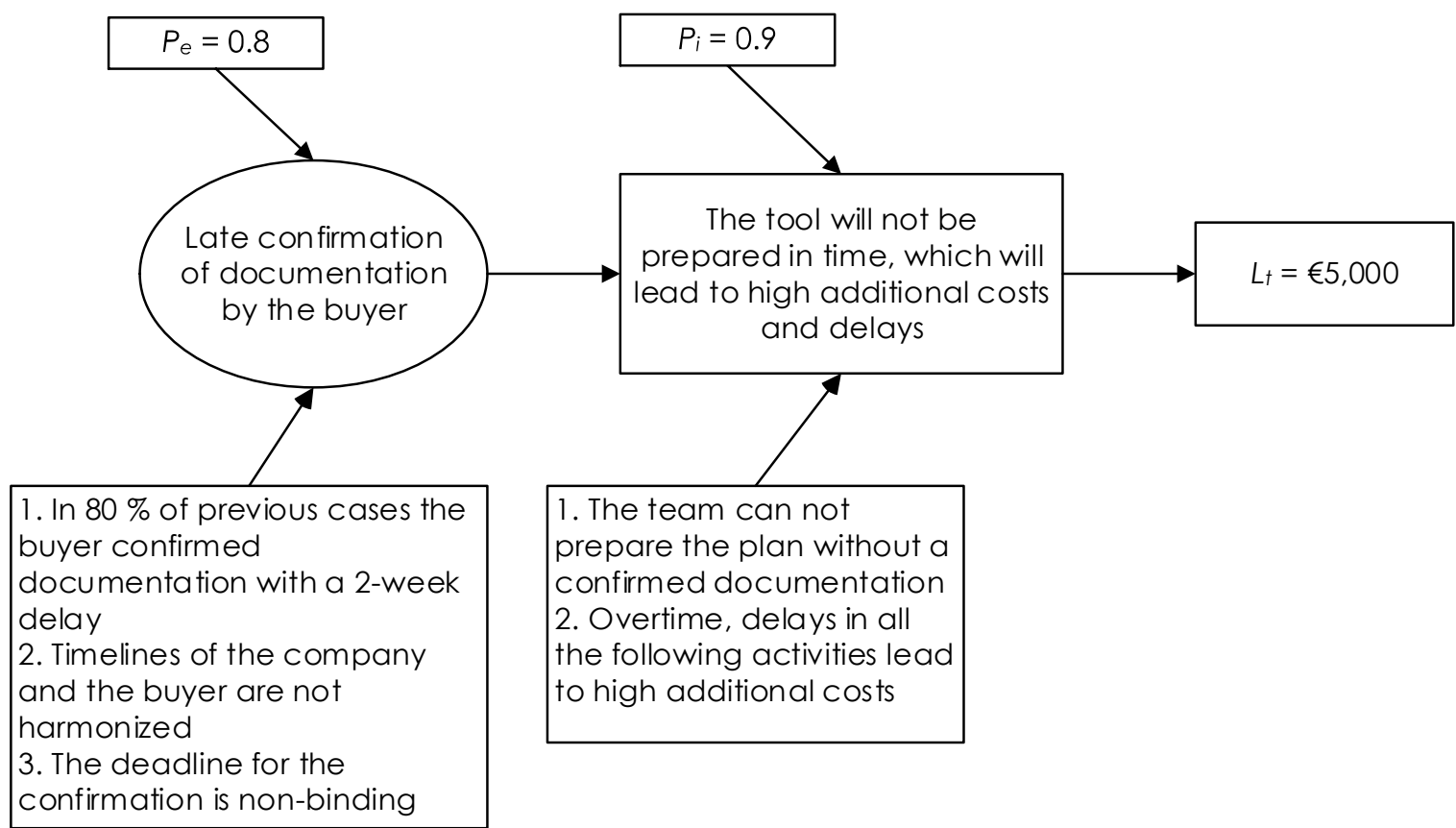

Source: Author's illustration

In the next step, the impact of the late confirmation of the documentation was analysed. If the documentation is not confirmed in time, then the plan for the tool will almost certainly not be prepared according to schedule. This further leads to overtime and delays in all the following activities, and the additional cost get very high. To lower the probability of the impact, it was decided to send a written request in case the buyer is still late in confirming the documentation, despite the harmonized timelines (measure 2). In that case, the buyer usually provides the confirmation quite rapidly, and the probability for the tool plan not being prepared in time was assessed to reduce to $50 \%$. The expected loss is thus lowered to $€ 875$, which is within the safe area.

The results of the prepared measures are summarized in Table 2. The basic risk is denoted with $\mathrm{R} 1$, the risk after the measure 1 with $\mathrm{R} 1.1$, and the risk after the measure 2 with R1.2. The impact of the measures is also evident on the risk map shown in Figure 5 .

Table 2

Resolving risk R1: Impact of the planned measures on the expected loss

\begin{tabular}{|c|c|c|c|c|c|}
\hline Risk & $P_{e}$ & $P_{i}$ & $P_{e} \cdot P_{i}$ & $L_{t}[€]$ & $L_{e}[€]$ \\
\hline R1 & 0.8 & 0.9 & 0.72 & 5,000 & 3,600 \\
\hline R1.1 & 0.7 & 0.9 & 0.63 & 2,500 & 1,575 \\
\hline R 1.2 & 0.7 & 0.5 & 0.35 & 2,500 & 875 \\
\hline
\end{tabular}

Source: Author's work 
Figure 5

Risk Map for Risk R1 (R1: the initial risk level: R1.1: the risk level after the measure 1; R1.2: the risk level after the risk measure 2)

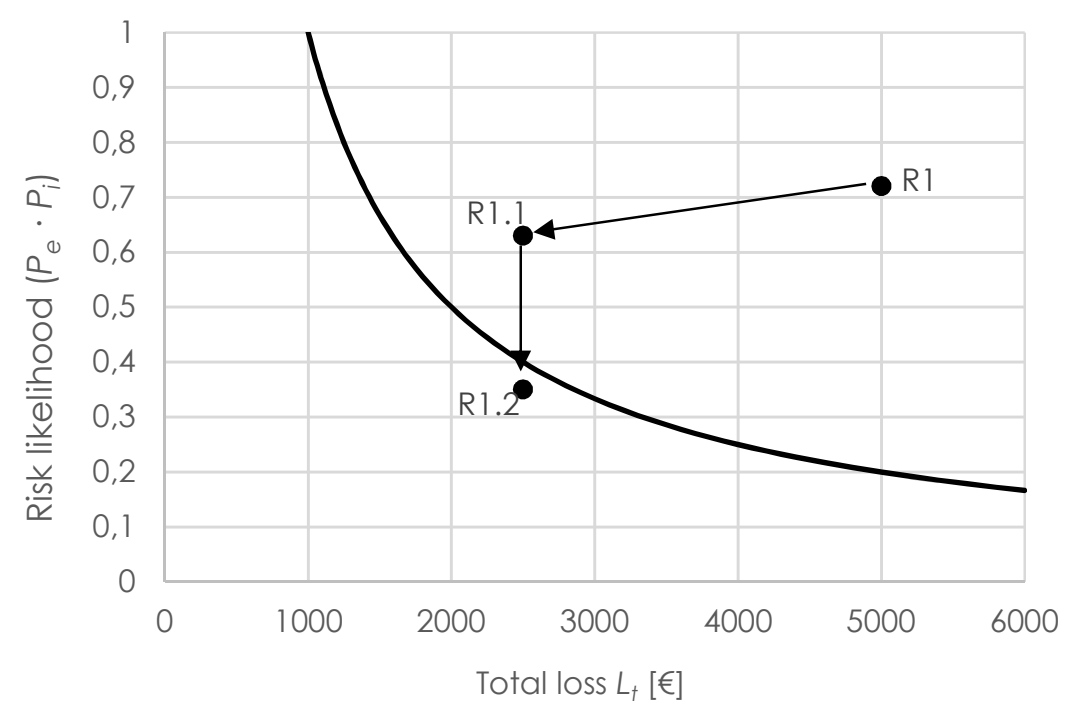

Source: Author's illustration

\section{Discussion}

The use the standard project risk analysis approach was shown on the die-cast tool development project. The approach was used for a quick evaluation and prioritization of the identified project risks, and it served as a very helpful basis for resolving risks. The graphical representation of risks allowed for a quick identification of the critical risks and therefore enabled a quick decision, on which risks to focus. With different preventive measures (measure 1) and corrective measures (measure 2), the project team managed to significantly lower the risk levels.

The main advantage of the approach is its simplicity. The severity of the identified risks can be quickly evaluated according to the standard risk model. The calculations are simple and rather intuitive even to a non-expert. The quantification of loss is also very beneficial when prioritizing project risks.

Another great advantage of the standard risk model is a separate treatment of the risk event and the impact, which clarifies the cause and the effect, and thus allows for a separate planning of preventive and corrective measures (Merritt \& Smith, 2004). The effect of individual measures can be easily monitored on the risk map.

The proposed approach is also very transparent and clear. In the risk map, one can instantly find the critical risks that need special attention. The introduction of the isorisks makes sure that the risks that lead to the same expected loss fall in the same risk area. In that sense, the presented approach can also serve as a reliable decision-making prompt.

However, the approach has some drawbacks. First, one must be aware that the assessments of the probabilities and total losses are subjective in nature and can lead to a significant error. The error can be lowered to some extent with the introduction of discrete scales and expert groups, however, the results always represent just a rough estimate.

Second, the standard risk model does not allow multiple risk events to converge on a single impact (Smith \& Merritt, 2002). In addition, the correlations between different risks are not taken into account. If a risk is treated as a single isolated entity, it may seem rather insignificant, even though it can be correlated to other highly critical risks. 
The correlations between risks are crucial for effective risk management and will be addressed in further research.

\section{Conclusion}

Effective risk management is a key to a successful project. One of the basic steps of a risk management process is a risk analysis. In the paper, we presented a standard project risk analysis approach that combines a standard risk model and a risk map. The use of the presented risk analysis approach was illustrated on a die-cast tool development project and it proved to be very useful. The analysed project was rather simple and the main goal was to get an evaluation of risks levels quickly. For more complex projects, the developed approach might not be sufficient and at least an additional correlation analysis should be made.

Even though there are some drawbacks to the proposed approach, it can be very helpful when a quick risk evaluation must be made. The separate treatment of risk events and impacts also allows for an easier and more effective planning of preventive and corrective measures and therefore serves as a good basis for resolving risks in the following steps of a risk management process.

\section{References}

1. Aven, T. (2016), "Risk assessment and risk management: review of recent advances on their foundation", European Journal of Operational Research, Vol. 253, No. 1, pp. 1-13.

2. Baccarini, D., Archer, R. (2001), "The risk ranking of projects: a methodology", International Journal of Project Management, Vol. 19, No. 3, pp. 139-145.

3. Chauhan, A. S., Nepal, B., Soni, G., Rathore, A. P. S. (2018), "Examining the state of risk management research in new product development process", Engineering Management Journal, Vol. 30, No. 2, pp. 85-97.

4. de Araújo Lima, P. F., Crema, M., Verbano, C. (2019), „Risk management in SMEs: a systematic literature review and future directions", European Management Journal, Vol. 38 , No. 1, pp. 78-94.

5. Ferdous, R., Khan, F., Sadiq, R., Amyotte, P., Veitch, B. (2011), "Fault and event tree analyses for process systems risk analysis: uncertainty handling formulations", Risk Analysis, Vol. 31, No. 1, pp. 86-107.

6. Krane, H. P., Rolstadås, A., Olsson, N. O. E. (2010), "Categorizing risks in seven large projects - Which risks do the projects focus on?" Project Management Journal, Vol. 41, No. 1, pp. 81-86.

7. Levine, E. S. (2012), "Improving risk matrices: the advantages of logarithmically scaled axes", Journal of Risk Research, Vol. 15, No. 2, pp. 209-222.

8. Li, J., Bao, C., Wu, D. (2018), "How to design rating schemes of risk matrices: a sequential updating approach", Risk Analysis, Vol. 38, No. 1, pp. 99-117.

9. Markowski, A. S., Sam Mannan, M. (2008), "Fuzzy risk matrix", Journal of Hazardous Materials, Vol. 159, No. 1, pp. 152-157.

10. Merritt, G. M., Smith, P. G. (2004), "Techniques for managing project risk", in Cleland, D. I. (Ed.), Field Guide to Project Management, 2nd edn., John Wiley \& Sons, New Jersey, pp. 202-218.

11. Ni, H., Chen, A., Chen, N. (2010), "Some extensions on risk matrix approach", Safety Science, Vol. 48, No. 10, pp. 1269-1278.

12. Project Management Institute. (2017), A Guide to the Project Management Body of Knowledge (PMBOK® Guide), 6th edn., PMI, Pennsylvania.

13. Smith, P. G., Merritt, G. M. (2002), Proactive Risk Management: Controlling Uncertainty in Product Development, CRC Press, New York.

14. Tonchia, S. (2018). Industrial Project Management: International Standards and Best Practices for Engineering and Construction Contracting, 2nd edn., Springer-Verlag Berlin. 


\section{About the authors}

Tena Žužek is a PhD student and a young researcher in the Laboratory for Manufacturing Systems and Production Process Planning at the Faculty of Mechanical Engineering, University of Ljubljana. She received a bachelor's degree in physics and a master's degree in mechanical engineering from the University of Ljubljana. Her research interests include project management, risk management, concurrent engineering and agility. The author can be contacted at Tena.Zuzek@fs.uni-Ij.si

Lidija Rihar graduated from the Faculty of Mechanical Engineering of Ljubljana in the field of production systems in 2009. In 2013, she defended her doctoral dissertation entitled Generalized Model of Concurrent Product and Process Development. Her research fields include project management, concurrent engineering and teamwork. Since 2013, she has been a research assistant at the Faculty of Mechanical Engineering in the field of production systems. The author can be contacted at Lidija.Rihar@fs.uni-lj.si

Tomaž Berlec, Ph.D. is an assistant professor at the Faculty of Mechanical Engineering, University of Ljubljana, Slovenia. He obtained his M. Sc. degree in 2003 and a Ph.D. degree in 2008 in the field of production planning and control. His research fields include: lean production, teamwork, material flow optimisation in companies with individual and small-series production, lead times optimisation of operations and orders, production planning and control systems. In these fields, he published 21 original scientific papers in scientific journals and more than 60 papers in conference proceedings. The author can be contacted at Tomaz.Berlec@fs.uni-lj.si

Janez Kušar is an associate professor at the Faculty of Mechanical Engineering, University of Ljubljana, Slovenia. He took his Ph.D. in 1999 in the field of production planning and control. His research fields include project management, especially in individual and small-series production, material flow optimization, production planning and control systems, and projects of transition from sequential to concurrent engineering. In these fields, he published more than 20 original scientific papers in scientific journals and more than 60 papers in conference proceedings. He is a member of the IPMA - International Project Management Association and ICEC International Cost Engineering Council. The author can be contacted at Janez.Kusar@fs.uni-Ij.si 